\title{
Propuestas cronológicas para la Historia de la publicidad
}

\author{
Ma Dolores Fernández Poyatos \\ Universidad de Alicante \\ dolores.fernandez@ua.es
}

\begin{abstract}
Resumen
La mayoría de los investigadores considera que las primeras expresiones publicitarias se remontan a la Antigüedad; otros creen desproporcionada esta visión tan larga. Un tercer grupo lo integran aquéllos que adoptan criterios eclécticos. En este trabajo el objetivo ha sido, por una parte, reflexionar sobre por qué la historia de la publicidad cuenta en España con tan escasos estudios; y, por otra, ha sido mostrar las diferentes y más representativas propuestas cronológicas, partiendo de una clasificación propia que ordena la Historia publicitaria en dos modelos: generalista y restrictivo.
\end{abstract}

Palabras clave: Historia de la publicidad; cronología; España

\section{Chronological Proposals for Advertising History.}

\begin{abstract}
Most investigators believe that early advertising slogans date back to antiquity, others believe that this vision is disproportionate. A third group composed of those who adopt eclectic criteria. On the one hand, the objective of this work has been to reflect about why advertising history in Spain has so few studies and, on the other hand, it also has been to show the different and most representative chronological proposals, starting from a self-classification which classifies advertising history in two models: general and restrictive.
\end{abstract}

Key words: Advertising History; chronology; Spain

Referencia normalizada:

Fernández Poyatos, M. D. (2013) Propuestas cronológicas para la Historia de la publicidad. Historia y Comunicación Social. Vol. 18 No Especial Octubre. Págs. 267-277

Sumario: 1. Introducción. 2. Metodología. 3. Modelos de ordenación cronológica. 4. Conclusiones. 5. Referencias bibliográficas.

\section{Introducción}

La mayoría de los estudios sobre Historia de la publicidad sitúan su origen junto al de las primeras evidencias escritas; así el testimonio legado por un comerciante de Tebas, allá por el año 3.000 a. c., divulgando que recompensaría a quien le proporcionase noticias de un esclavo huido, está considerado la primera muestra publicitaria. Entre este suceso y el momento actual, se ajusta la cronología de la historia publicitaria que, en general, posee una parcelación bastante tradicional y coincidente con 
los períodos históricos clásicos (Historia Antigua, Medieval, Moderna y Contemporánea). Se inscriben aquí la mayor parte de los autores: teóricos españoles como Prat Gaballí, Aubeyzón, García Ruescas, Checa, y destacados analistas extranjeros como Leduc, Datz, Brown, Anaut y Ferrrer.

Sin oponerse a esta clasificación, pero sí con más restricciones, se hallan teóricos que afirman que "antes del siglo XIX lo que había, excepto quizá en la Inglaterra del siglo XVIII, eran anuncios", aunque a veces se emplee el término publicidad para calificar esas manifestaciones (Eguizábal, 1998a: 13). Y todo lo anterior a la imprenta - aseguran - ha de ser conceptuado de otra forma: avisos, reclamos, actividad anunciadora, anuncios comerciales..., pero desde luego no como publicidad. Estos autores fijan el nacimiento de la publicidad junto al de la Revolución Industrial. Bravo y Eguizábal adoptan este enfoque.

En tercer lugar, un juicio ecléctico sería el elegido por Sánchez Guzmán (1976: 15-16) al proponer que según la publicidad sea entendida como método de persuasión, como instrumento económico o como institución social, es posible considerar como fenómenos publicitarios determinados hechos sociales de épocas diferentes, o bien ser rechazados como tales. Juicio éste resultado de un problema largo sobre la cuestión histórica como es el de la poca atención que ha suscitado entre historiadores y profesionales publicitarios de nuestro país. Respecto a esto, Sánchez Guzmán hacía suyas las reflexiones de Lagneau, quien ya en 1969 advertía de este hecho y quien, igualmente, señalaba las divergencias que ello provocaba en el estudio histórico, resultado del hábito generado entre aquellos que se acercan al tema de "tomar lo que otros dijeron" (1976: 15).

Es fácil constatar la presencia, en muchos de los tratados sobre publicidad, de un primer capítulo sobre la Historia. Al mismo tiempo, es frecuente que esas primeras líneas no sean más que una mixtura de datos recogidos de estudios precedentes que, por lo general, no aportan casi nada nuevo. Así, la narración del esclavo egipcio huido es ya todo un clásico en la literatura publicitaria del que, hay que decirlo, nadie aporta documentos.

¿Por qué la investigación se ha resignado con noticias y hechos de hace ya demasiados años? Quizá la respuesta esté en el insuficiente interés del ámbito histórico entre los investigadores; lo pertinente sería, entonces, preguntarse por el abandono de la vertiente histórica, cuestión que, por otra parte, se está revelando y reclamando en los últimos años. Precisamente, y a propósito de la ignorancia que profesionales y estudiantes tienen de Prat Gaballí, Alvarado considera que no sólo es significativo dicho desinterés, sino que también lo es la "despreocupación por el pasado de una profesión en la que todo es efímero y que necesita reinventar conceptos constantemente" (2002: 1).

En efecto, lo transitorio y fugaz del mensaje publicitario provoca que la profesión publicitaria sienta que sus conceptos, y también sus productos - los mensajes publicitarios- estén contagiados de esa misma obsolescencia y perentoriedad; apremio que, quizá, los haga poco valiosos como objeto de estudio. Sin embargo, es justo 
considerar que, dada la institucionalización reciente (1971) de los estudios de publicidad en nuestro país, no ha sido posible desarrollar una faceta de dichos estudios como es la de la Historia. Por el contrario, la vertiente histórica de la publicidad cuenta en algunos países - Estados Unidos y Gran Bretaña - con una larga y fructífera tradición investigadora. Tanto la historia en general, como aquélla que concierne a agencias y anunciantes autóctonos, han sido copiosamente estudiadas.

Una explicación sobre la escasez de estudios historiográficos podría descubrirse en la mala fama que ha perseguido a la publicidad desde sus orígenes; una disciplina en la que sus profesionales -los publicitarios- "know very little about theirs, almost as though they were afraid of what they might find if they were to dig too far beneath the surface" (Nevett, 1977: 15).

En el marco de un curso monográfico sobre medición, investigación e información publicitarias celebrado en 1996, se planteó la pregunta ¿Tiene la publicidad buena prensa? a personas relevantes adscritas diversos sectores publicitarios. Desde los anunciantes, su presidente Córdoba Villar propuso escudriñar en la historia, afirmando que el mayor desprestigio se alcanzó tras la Segunda Guerra Mundial por los estragos originados por la propaganda del III Reich:"por cierto contagio de lo que había sucedido durante esos años, se empezó a meter a la publicidad en el mismo saco que a la propaganda" (1996:186-187).

Para Gómez Castallo, entonces director general del Instituto Nacional de Consumo, "el aspecto más negativo [reside en] la falta de veracidad de algunos mensajes publicitarios" (1998: 188-189). Es cierto que, bajo una forma u otra, la exageración y el engaño se le han atribuido a la publicidad desde sus inicios. Así, el sector de las medicinas patentadas, muy vinculado a los pioneros publicitarios, ocasionó a la profesión pingües beneficios, pero también un justificado descrédito.

En España, esta publicidad fue vital también para el desarrollo de la actividad publicitaria y de la prensa, representando a finales del siglo XIX más de un tercio de los anuncios de la prensa ilustrada y más de la mitad de los diarios (Fernández Poyatos, 2011: 7).

La impopularidad y el desprestigio de los fraudulentos medicamentos milagrosos alcanzó a los publicitarios hasta el punto de que, precisamente en Estados Unidos, fueron ellos mismos los encargados de perseguir esta publicidad mendaz, así como a todo aquel que la practicaba.

Furones (1996: 193-194), presidente entonces de la Asociación Española de Agencias de Publicidad, respondió con la descripción de un anuncio aparecido la prensa norteamericana en defensa de la publicidad:

En ella se veía toda una página de anuncios por palabras: se vendían pisos, coches, se solicitaban citas, etc. En el centro, muy destacado, tan sólo un titular: Es curioso cómo la gente cambia su opinión sobre la publicidad en cuanto tiene algo que vender.

Por último, Subirats — directora del Instituto de la Mujer en 1996 - aportó razones por las que también creía que la publicidad carecía de buena prensa: primero, 
porque, sirviendo a intereses privados, ocupa enormes recursos y espacios colectivos; segundo, por su mendacidad y, tercero, porque la publicidad "va envuelta en una venta de otras cosas, el producto va envuelto en unas formas de vida, en unos conceptos, en sugerir una serie de situaciones, etc." (1996: 194), de manera que en relación a las mujeres (y a los hombres), se dan una serie de estereotipos que son formas del pasado, formas que hoy, ya no son verdad, que están caducas.

En síntesis, la conclusión unánime de los participantes en las jornadas indicadas fue que, en efecto, la publicidad tenía "mala prensa". No es extraño, pues, que una actividad con tales características — obsoleta, manipuladora, poco veraz, atrasada, de un pasado sospechoso e incierto y emparentada con intereses capitalistas - resulte poco interesante para la investigación. Algo de todo esto ha de haber, ya que existen escasísimos estudios historiográficos en, y sobre, nuestro país.

En lo referente al caso español, desde que García Ruescas escribiera en 1971 la primera Historia de la publicidad en España, sólo se han publicado dos trabajos globales: La publicidad en España. Anunciantes, agencias y medios. 1850-1950 (2001) y La transición de la publicidad española. Anunciantes, agencias y medios. 1950-1980 (2003) de Pérez Ruiz y los recientes volúmenes de Montero et alter (2010) sobre la Historia de la publicidad y las relaciones públicas en España. Aún sin publicar, hay que mencionar también la tesis doctoral Orígenes y evolución de la actividad publicitaria en España. 1880-1936, de Fernández Poyatos, quien concluye que la actividad publicitaria moderna se inició en nuestro país a finales del siglo XIX y se consolidó en su modernidad en el primer tercio del siglo XX.

Este breve, y desalentador panorama, se repite cuando se trata de obras históricas universales, ya que las existentes están formadas por tratados que en muchos casos son breves, o quedan rematados por algún anexo que los acompaña: Sánchez Guzmán y su Breve historia de la publicidad, o Puig y La Publicidad: historia y técnica. Destaca, empero, el trabajo de Eguizábal — Historia de la publicidad - con un apéndice de más de un centenar de páginas sobre la publicidad española que se compaña de un profuso apartado bibliográfico.

\section{Metología}

Dada la escasez de investigaciones sobre la historia de la publicidad en nuestro país y dada la falta de acuerdo sobre el significado y alcance del término publicidad, que provoca diferentes parcelaciones cronológicas entre los estudiosos, nuestro objetivo se ha orientado hacia el análisis de las distintas aproximaciones históricas, buscando hallar los puntos en común, las divergencias y la progresión en el estudio de los datos, desde el primero del que tenemos noticia - Aubeyzón - hasta el trabajo de Checa. Para ello, hemos revisado, primero, sucesos históricos claves para la evolución de la humanidad - y por ende, para el curso de la publicidad-, y segundo, aquellos acontecimientos privativos del proceso publicitario. Ha de entenderse así que hayamos prescindido de numerosos datos, fechas, acontecimientos..., pues su 
sola enumeración hubiera desbordado los límites y el sentido de este trabajo. Se ha utilizado, por tanto, bibliografía de época y bibliografía contemporánea.

De otro lado, la pauta elegida para seleccionar las obras que se exponen ha sido la de hacerlo sobre autores de habla hispana que, interesados por la vertiente histórica de la publicidad, le han dedicado un estudio completo o, cuando menos, relevante y fértil. Los libros y autores consultados para la elaboración de dicho cuadro han sido los siguientes: Aubeyzón (¿1928?), Prat Gaballí (1953, 1959), Bravo (1971), Sánchez Guzmán (1976), Ferrer (1980), Puig (1986), Anaut (1990), Eguizábal (1998) y Checa (2007).

\section{Modelos de ordenación cronológica}

Las dificultades que implica elaborar una cronología histórica general crecen cuando se aborda ésta desde sus primeras etapas; máxime si su objeto es la publicidad, pues las formas de expresión y de comunicación que se desarrollan son difíciles de valorar, primero, y de clasificar, después. A mayor abundamiento, no existe conformidad en aceptar un modelo único de división cronológica publicitaria, siendo las distintas propuestas resultado de la ya comentada parvedad de estudios, así como de las discrepancias en la precisión terminológica, esto es, de la falta de acuerdo sobre el alcance y el contenido de los términos «anuncio» y, sobre todo, «publicidad». Recordemos las doscientas definiciones de Ferrer (1980: 99-139), enriquecidas con un apartado de definiciones históricas y un resumen de descripciones lexicográficas.

Entendemos que éste es uno de los escollos principales que la investigación encuentra cuando aborda la historia publicitaria. Según la consideración que de dichos términos se haga, derivarán dos clasificaciones: 1) Generalista y 2) Restrictiva.

1) Opción Generalista. Se inscriben aquí autores que datan el origen de la publicidad junto al de las primeras manifestaciones escritas; incluso antes, como es el caso de Aubeyzón y Prat Gaballí, quienes se retrotraen a los umbrales bíblicos con la serpiente, Noé y la estrella de Belén. Para el primero (¿1928?: 11-12), la publicidad

ha venido usándose desde que la Tierra fue habitada. Hay quien sitúa su origen en el acto de ofrecer la manzana la serpiente a nuestro padre Adán, [....] Aquella serpiente [...] supo hacer pasar a Adán por los mismos estados de ánimo que un comerciante actual procura hacer pasar a sus posibles y deseados clientes: Cautivó su atención; avivó su interés; le hizo nacer el deseo; conquistó su voluntad y, si bien no le hizo llegar al acto material de la compra [...] obtuvo todo cuanto ella deseaba. A partir de este acto, la Historia Sagrada contiene una diversidad de acontecimientos que podríamos calificar de publicitarios, los cuales enumeraríamos si no nos asaltara el temor de ser tildados de irreverentes.

Temor que no debía sentir Prat Gaballí (1959: 1) cuando adelantó algún hecho sagrado más: 
La Sagrada Biblia revela los primeros balbuceos publicitarios del hombre, para el Bien y para el Mal. Fueron para el Mal cuando la serpiente dijo a nuestros primeros padres: ¿Por qué no coméis de todos los frutos de este jardín? Fueron para el Bien cuando el viejo Noé anunció el Diluvio Universal y cuando los profetas pregonaron hechos y leyes. Milenios más tarde la publicidad se manifestaba como emanación divina en la Estrella de Belén.

Incluso algún publicitario coetáneo se retrotrae a épocas lejanas para anunciar que el primer publicitario fue Dios cuando le entregó las Tablas de los Diez Mandamientos a Moisés (Castellblanque, 1997: 21-22).

Lenguaje figurado aparte, la opción generalista asume cinco etapas en el acontecer publicitario ajustadas entre los primeros restos hallados en las civilizaciones antiguas -Egipto, Méjico, Mesopotamia, Grecia...- y el siglo XX, con una parcelación coincidente con los períodos históricos clásicos : Historia Antigua, Medieval, Moderna y Contemporánea.

2) Opción restrictiva. De los tratadistas clásicos, Prat Gaballí anticipó en 1917 esta alternativa a la que Bori y Gardó volvieron a dar vigencia en 1936 cuando estimaron que las primeras muestras (inscripciones electorales asirias, enseñas de mesones, etc.) "si bien son precursoras de la Publicidad actual no pueden conceptuarse comprendidas dentro de la ciencia publicitaria” (1936: 23). Prat Gaballí lo hizo en sus célebres conferencias a propósito del primer curso de publicidad que se impartió en España. Si consideraba, como decíamos en la opción generalista, que la publicidad es tan antigua como el comercio, también es cierto que matizó y aclaró dicha afirmación cuando, líneas después, escribía que "la verdadera historia de la Publicidad como factor económico poderoso tiene su fuente madre [en 1850, marcando el año 1895] la intervención de la ciencia tanto en su forma como en su espíritu" (1917: 12), proponiendo tres definiciones evolutivas para la voz publicidad:

- Hasta 1850, la publicidad ha sido el conjunto de medios destinados a dar a conocer los productos, "expresando o sin expresar las ventajas particulares de marca o de nombre, para venderlos casi exclusivamente en la medida de las necesidades del público".

- Entre 1850 y 1895, una vez que la economía deja de producir para sobreproducir, la publicidad es "el conjunto de medios destinados a dar a conocer 'al mayor número posible de individuos' los productos [...] 'expresando precisamente ventajas particulares de marca o nombre en forma llamativa”.

- A partir de 1895, y hasta el momento actual, una vez que triunfa la orientación científica, la publicidad "es la ciencia que enseña a conocer el espíritu del público y a aplicar este conocimiento a los medios de que disponen la imaginación y el ingenio para dar noticia al mayor número posible de individuos de la utilidad o las ventajas de un artículo, en forma que ejerza una acción eficaz, es decir, que llegue a sugerir deseos y a determinar actos de voluntad".

De forma que, hasta mediados del siglo XIX, la publicidad era equivalente a dar a conocer mercancías, sin voluntad de marca, y destinada a cubrir, fundamentalmente, 
necesidades. Después, la publicidad comenzó a utilizarse como una herramienta eficaz para dar salida a la sobreproducción de artículos ya marcados, o lo que es lo mismo, se entendía ya como un acelerador del consumo. A partir de 1895 , y en los grandes países activos, sobre todo Estados Unidos, la publicidad discurre por el camino del método y de la ciencia, que no es otro que conseguir de ella una acción eficaz, capaz de provocar deseos y de mover la voluntad.

Por su parte, Bravo (1971: 31-40) propone distinguir entre noticias, comunicados, anuncios y publicidad; según se trate de unos u otros, estaríamos ante las tres grandes etapas históricas siguientes: 1) Antecedentes; 2) Anuncios y 3) Publicidad.

En la primera, se ubicarían las noticias orales - de boca a oreja-, contengan o no asuntos comerciales, así como los simples comunicados «hago saber», «se busca», etc. A este tipo de manifestación, considera Bravo, no se le puede denominar publicidad.

En el segundo período, es posible hallar formas de información comercial —los anuncios-, que son tales cuando contienen hechos comerciales y no "de justicia, religiosos, ciudadanos, políticos, etc..." (Bravo, 1971: 17). Coincide esta etapa con la aparición de la imprenta y con la reactivación mercantil. Dos hechos fundamentales para una actividad como la publicitaria, cuyo desarrollo depende de una señalización verbal - la palabra - y de una acción económica — el comercio-

Cuando el anuncio, trascienda esta naturaleza informativa y devenga en instrumento de venta, nos hallaremos en la tercera, y última, fase: la denominada, certeramente, publicidad. El hito que marca este período es algo más que la aparición de la agencia técnica, como algunos han señalado, es la correlación y la interdependencia de los agentes que integran el inicio de la acción publicitaria: medios, anunciantes y agencias, convirtiéndose éstas últimas en el elemento dinamizador de toda la actividad y sirviendo de nexo a los dos primeras (Bravo, 1971: 34).

De similar parecer es Eguizábal, quien añade a la precisión terminológica la noción de sistema que servirá para aclarar, delimitar y enriquecer los conceptos tratados (1998a: 9-15). Si asimilamos el término publicidad al de sistema y si entendemos por sistema un "Conjunto de reglas o principios sobre una materia enlazados entre sí" (R.A.E., 1984: 1250), se observa que hasta la aparición de la agencia esto no sucede: "Antes de que hubiese publicidad había anuncios [...] pero no un sistema [ya que] no hay continuidad estricta de unos a otros. [...] La publicidad es un fenómeno estrictamente moderno, fruto del siglo XIX, y la publicidad moderna es el resultado de la aparición de la agencia técnica, a comienzos del siglo XX" (Eguizábal, 1998a: 13).

Creemos interesante añadir a este criterio una cuestión que otros investigadores sugieren: el doble aspecto que una aproximación a la publicidad requiere, y que hallamos plasmado en dos acepciones: por un lado, la «publicidad comercial», que nace en el siglo XVIII con una clara finalidad económica determinada por las leyes del mercado, y a la que los norteamericanos denominan advertising. Por otro, está el concepto de publicity, de origen remoto, y entendido, sobre todo, como escenario en 
el que se comunican grupos sociales, individuos e instituciones. A esta concepción de la publicidad, no se le ha concedido "la importancia que requiere y que atiende y se preocupa de las formas de «publicitar» la comunicación en su sentido más amplio, o los aspectos de la privacidad, dentro de un contexto social construido al efecto" (1997: 187). De manera que, si se quiere comprender correctamente la publicidad, ésta ha de ser entendida bajo el doble prisma de lo económico y de lo comunicativo. La ignorancia de este doble aspecto conduce a innumerables equívocos (Benavides, 1997: 187).

\section{Conclusiones}

Para entender claramente nuestro objeto de estudio y poder hablar de los estereotipCualquier aproximación a la publicidad ha de reconocer dos aspectos que le son consustanciales: el comunicativo y el económico; o, cuando menos, no confundirlos ni eliminar uno a favor del otro (Benavides, 1997: 187).

Cuestión ésta que revela otra característica sobre la que advierte la investigación y con la que se encuentra cualquier aproximación a la disciplina publicitaria: la dificultad de aprehender el fenómeno publicitario como resultado de las distintas perspectivas bajo las que éste puede ser analizado: económica, social, cultural, mediática... En el primer caso, la publicidad se asume como herramienta del marketing e instrumento de consumo. En el segundo, hablaríamos de ella como factor de socialización. Desde el prisma cultural, la publicidad se ha consolidado como un símbolo de nuestra sociedad y, por último, el enfoque mediático, que no haría sino refrendar la función de comunicación a nivel instrumental (Benavides, 1997).

Nosotros creemos que la publicidad, como fenómeno histórico, debe ser considerada dentro de un ciclo, con un proceso de gestación y con un desarrollo que alcanza edades, es decir, que atraviesa por distintos período históricos como hecho social, económico y cultural que es, para madurar al fin en las dos últimas centurias. De ahí pues, la conveniencia de apellidarlo y también de asumir que sólo a partir del siglo XIX adquiere el sentido que posee en la actualidad. Cabría entonces hablar, primero, de unos antecedentes circunscritos a la Edad Antigua donde comerciantes y pregoneros anunciaban mercancías, bien con letreros, bien con su voz. Tras ella, los casi mil años de Edad Media en la que la sociedad, la economía y la cultura se replegaron, y que supondría una continuación de la primera fase (Pirenne, 1989). La aparición de la imprenta y el impulso formativo y comercial de la Edad Moderna inaugurarían la era de los anuncios; por último, a finales del siglo XIX, nace la publicidad moderna.

De manera que de publicidad, en su sentido actual, sólo es posible hablar cuando los factores que intervienen en el proceso de comunicación publicitaria convergen y se interrelacionan, esto es, los anunciantes, los medios y las agencias de publicidad. Estamos hablando en el primer caso de la empresa industrial moderna, ya que no sólo fue la protagonista de la transformación de las economías occidentales, sino la responsable de la disolución de la cadena productor-almacenista-detallista, así como 
de la modificación de las directrices de la demanda. Procesos que se consiguieron, fundamentalmente, a través de la publicidad que, entre otras funciones, se encargó de la diferenciación de los productos y de la aceleración de la demanda. Los medios segundo de los factores involucrados en la comunicación publicitaria - iniciaban, en la misma época, el camino hacia la modernidad. El periódico, soporte de las ideologías al uso, se emancipó merced a los ingresos de la partida publicitaria, adquiriendo así su sentido contemporáneo. A finales de la segunda década del siglo XX, el proceso fue idéntico para la radio, que sólo arrojó saldos positivos cuando se sirvió de la publicidad como fuente de financiación. Tanto uno, como otro, fueron conscientes de su valor como soportes publicitarios.

Por último, la agencia también adquirió a finales del XIX su conformación actual. $\mathrm{Si}$, en su origen, fueron mediadores entre anunciantes y medios, pronto las agencias entendieron que la función que les daba sentido iba a ser la de gestionar la comunicación del anunciante: idear, realizar y difundir los mensajes publicitarios, cuya viabilidad sólo iba a ser posible a través de medios y soportes.

En cualquier caso, se trate de avisos, noticias comerciales, hechos anunciadores o publicidad, lo más claro es que a la publicidad le falta una reflexión sobre su memoria. Creemos entonces que una cuestión acerca de su mala prensa se verá, no sólo aclarada con algo más de rigor, sino también enriquecida por la perspectiva histórica. Igualmente, presumimos que, a través del estudio de sus inicios y su evolución, todos aquellos atraídos por el hecho publicitario podrán contemplar el pasado sin el temor al que aludía Nevett. Sólo investigando los hechos, lo sabremos.

\section{Bibliografía}

ALVARADO LÓPEZ, M. C. (2010). Educar para vender: un caso emblemático de publicidad educativa en la España de 1930. http://www.portalcomunicacion. com/bcn2002/n_eng/programme/prog_ind/papers/a/pdf/a006_alvar.pdf. [13-072013].

AUBEYZÓN, Juan (¿1928?). "Datos y documentos para la Historia de la Publicidad”. En Curso de Publicidad y Organización. Barcelona: Cultura. p. 11-34.

BENAVIDES DELGADO, J. (1997). Lenguaje publicitario. Madrid: Síntesis.

BORI, R. y GARDÓ, J. (1936). Tratado completo de Publicidad y Propaganda. Barcelona: Biblioteca del hombre de negocios moderno, José Montesó editor.

BRAVO, J. (1971). "El papel de las agencias en la historia de la publicidad". En: Publicidad, no 28, p. 31-40.

CASTELLBLANQUE, M. (1997). Manual del redactor publicitario. Barcelona : CIMS.

CÓRDOBA VILLAR, J. L. (1996). "Los protagonistas opinan: ¿Tiene la publicidad buena prensa?". En CARO, A. y EGUIZÁBAL, R. (eds.). Medición, investigación e información de la Publicidad. Madrid: Comunicación 2000. p. 186-187.

CHECA, A. (2007). Historia de la publicidad. La Coruña: Netbiblo. 
EGUIZÁBAL, Raúl (1998a). Historia de la publicidad. Madrid: Eresma \& Celeste Ediciones.

(1998b): "Presentación". En: Publifilia. Revista de Culturas Publicitarias, n 1, Segovia, p. 5-6.

FERNÁNDEZ POYATOS, M. D. (2006). Orígenes y evolución de la actividad publicitaria en España. 1880-1936. Alicante: Universidad de Alicante. http://rua.ua.es/ dspace/handle/10045/11191: [7-08-2013].

(2011): La publicidad de la salud en la prensa ilustrada del siglo XIX, en Questiones publicitarias, vol I, $\mathrm{n}^{\circ} 16$, pp. 103-119. http://www.maecei.es/pdf/n16/articulos/A7.La_publicidad_de_salud_en_la_prensa_ilustrada_de_finales_del_siglo_ XIX.pdf: [7-10-2012].

FERRER, E. (1980). La publicidad. Textos y conceptos. México: Trillas.

FURONES, M. Á. (1996): "Los protagonistas opinan: ¿Tiene la publicidad buena prensa?". En CARO, A. y EGUIZÁBAL, R. (eds.). Medición, investigación e información de la Publicidad. Madrid : Comunicación 2000. p. 93-94.

GARCÍA RUESCAS, F. (1971). Historia de la publicidad en España. Madrid : Editora Nacional.

GÓMEZ CASTALLO (1996). "Los protagonistas opinan: ¿Tiene la publicidad buena prensa?”. En CARO, A. y EGUIZÁBAL, R. (eds.). Medición, investigación e información de la Publicidad. Madrid: Comunicación 2000. p. 188-189.

MONTERO, M., RODRÍGUEZ, N. y VERDERA, F. (coords.) (2010). De la nada al consumo. Desde los orígenes hasta 1960. Zamora: Comunicación social.

NEVETT, T. (1977). "London's Early Advertising Agents". En Journal of Advertising History, p. 15-17.

PÉREZ RUIZ, M. Á. (2001). La publicidad en España. Anunciantes, agencias y medios. 1850-1950. Madrid: Fragua.

PÉREZ RUIZ, M. Á. (2003). La transición de la publicidad española. Anunciantes, agencias y medios. 1950-1980. Madrid: Fragua.

PIRENNE, H. (1989). Historia económica y social de la Edad Media. Madrid: Fondo de Cultura Económica.

PRAT GABALLÍ, P. (1917). Una nueva técnica: la publicidad científica. Lecciones explicadas en las Clases de Enseñanza Mercantil de dicha Corporación durante el Curso 1915-1916. Barcelona: Imprenta de Henrich y C. ${ }^{\text {a }}$

PRAT GABALLÍ, P. (1959). Publicidad combativa. Barcelona: Labor.

REAL ACADEMIA ESPAÑOLA DE LA LENGUA (1984). Madrid: Espasa-Calpe.

SÁNCHEZ GUZMÁN, J. R. (1976). Breve Historia de la publicidad. Madrid: Pirámide.

SUBIRATS MARTORÍ, M. (1996): "Los protagonistas opinan: ¿Tiene la publicidad buena prensa?". En CARO, A. y EGUIZÁBAL, R. (eds.). Medición, investigación e información de la Publicidad. Madrid : Comunicación 2000. p. 194. 


\section{La autora}

Ma Dolores Fernández Poyatos es Doctora por la Universidad de Alicante, con la tesis: "Origen y evolución de la actividad publicitaria en España. 1880-1936". Profesora del Dpto. de Comunicación y Psicología social (Universidad de Alicante); investigadora en diversos proyectos de investigación y autora de diversas publicaciones. Desarrolla su actividad docente e investigadora en el área de la Historia de la publicidad, la Comunicación turística y la Estrategia publicitaria. 